\title{
PEMAKSAAN DALAM PENDIDIKAN DAN PRESTASI BELAJAR
}

\author{
Nurbaiti \\ Universitas Islam Negeri Syarif Hidayatullah Jakarta \\ (DPK Sekolah Tinggi Agama Islam ALHIKMAH Jakarta) \\ nurbaiti.uin@gmail.com
}

\section{Abstract}

This research was conducted at the Lirboyo Islamic Boarding School, East Java. The purpose of this study is to find out about coercion in education and its contribution to student achievement. We used 65 sample and we used mixed research method. We used triangulation as the qualitative data validity, and we used the product moment correlation coefficient and the biserial point correlation coefficient as the quantitative data validity. We used data reliability by alpha cronbach and KR 21. The results showed, the form of coercion in this boarding school by giving sanctions (punishment). The results also showed, there was a positive and significant correlation between giving sanctions to student achievement and sanctions had a contribution to student achievement of 39.60 percent.

Keywords: Islamic Boarding School, Students, Coercion, Education, Sanctions. 


\section{Abstrak}

Penelitian ini dilakukan di Pondok Pesantren Lirboyo, Jawa Timur. Tujuan dari penelitian ini adalah untuk mengetahui tentang pemaksaan yang dilakukan dalam pendidikan dan kontribusinya terhadap prestasi belajar siswa. Jumlah sample dalam penelitian ini sebanyak 65 orang dan metode yang digunakan adalah metode penelitian campuran (mixed method). Validitas data secara kualitatif dengan menggunakan triangulasi, secara kuantitatif dengan menggunakan koefisien korelasi product moment dan koefisien korelasi point biserial. Reliabilitas data digunakan dengan alpha cronbach dan KR 21. Hasil penelitian menunjukkan, bentukpemaksaanyang dilakukan di pondokpesantren ini dengan memberikan sanksi (punishment) terhadap pelanggaran yang dilakukan santri. Hasil penelitian juga menunjukkan terdapat hubungan yang positif dan signifikans antara pemberian sanksi terhadap prestasi belajar siswa dan pemberian sanksi memiliki kontribusi terhadap prestasi belajar siswa sebesar 39.60 persen.

Kata Kunci: Pondok Pesantren, Santri, Pemaksaan, Pendidikan, Sanksi. 


\section{A. PENDAHULUAN}

$\mathrm{P}$ endidikan merupakan usaha sadar yang dilakukan agar terjadi perubahan ke arah kebaikan, sehingga melalui pendidikan diharapkan peserta didik tidak hanya memiliki kecerdasan secara intelektual, tetapi juga memiliki kecerdasan dalam bersikap.

Hal ini dapat diartikan bahwa dalam melakukan pendidikan guru tidak hanya mentransfer ilmu pengetahuan saja, tetapi juga mengarahkan peserta didik agar memiliki akhlak yang baik. Seperti dinyatakan oleh Brannen bahwa pendidikan merupakan usaha manusia yang paling mulia, karena melalui pendidikan memungkinkan manusia mencapai pribadi, spiritual, mental dan potensi fisik yang baik. Kemampuan dididik inilah yang membedakan manusia dengan hewan. ${ }^{1}$

Pendidikan dalam perspektif Islam menurut Ham, merupakan setiap usaha yang ditujukan untuk mendidik dan membangun kepribadian pada semua aspek. Baik aspek spiritual, emosional, moral dan lain sebagainya. ${ }^{2}$ Hal yang sama juga dinyatakan oleh Firdaus dan Jani, pendidikan dalam Islam tidak hanya untuk memperoleh pengetahuan intelektual, tetapi lebih kepada pembentukan karakter individu. Sehingga manusia dapat berperilaku sebagai khalīfatullāh fi al-ard (khalifah Allah di bumi). ${ }^{3}$

Dengan demikian, pendidikan merupakan usaha perbaikan agar terjadi keseimbangan kepribadian pada semua aspek hidup manusia, sehingga setelah menjalani proses pembelajaran peserta didik memiliki kecerdasan baik dalam hal kognitif, maupun afektif dan psikomotorik. Namun kenyataannya sampai saat ini masih banyak siswa yang memiliki prestasi belajar yang kurang baik dalam hal kognitif, afektif dan psikomotorik.

Hal ini dapat dilihat dengan masih rendahnya nilai yang

1 Anick Brennen. Essay on Education and Educational Pshycology. Booklet (Jamaica : Northern Caribean University : August, 2009), h. 4.

2 Ibrahim Mohammad Hamm, "Islamic Perspective of Education and Teachers", European Journal of Social Science 30,2 (2012), h. 224.

3 Raudatul Firdaus Binti Fatah Yasin and Mohd.Shah Jani."Islamic Education: The Phylosophy, Aim, and Main Feature."International Journal of Education and Research 1,10 (Oktober, 2010), h. 14. 
diperoleh siswa dari proses pembelajaran, sehingga diperlukan suatu upaya untuk memperbaiki hal tersebut. Salah satu upaya yang dapat dilakukan adalah melalui pemberian sanksi. Hal ini dilakukan agar proses pembelajaran dapat berjalan dengan baik.

Pemberian sanksi harus diakui dapat memberikan dampak negatif pada siswa. Seperti dinyatakan oleh Arif dan Rafi, bagaimanapun sanksi fisik dapat memberikan dampak negatif terhadap siswa, bahkan siswa di Pakistan merasa takut datang ke sekolah karena adanya sanksi fisik. ${ }^{4}$ Meskipun demikian, Ormond mengganggap pemberian sanksi dalam proses belajar mengajar penting, karena belajar merupakan proses perubahan tingkah laku dan sanksi dapat merangsang stimulus siswa dalam berprilaku. ${ }^{5}$

Al-Fawzan menyatakan, Ibnu Khaldun (1332 -1406) meskipun menolak pemberian punishment (sanksi) kepada siswa karena dianggap berbahaya, dapat merusak moral dan mempengaruhi karakternya, serta berdampak pada perilaku peserta didik yang tidak diinginkan, namun pemberian sanksi diperbolehkan asalkan untuk memodifikasi perilaku tertentu, dan sebagai sarana untuk mencegah siswa melakukan kesalahan. ${ }^{6}$

Demikian juga dengan pernyataan Latif, Ibnu Sina (9801037) pada dasarnya tidak berkenan menggunakan sanksi dalam kegiatan pengajaran. Hal ini didasarkan pada sikapnya yang sangat menghargai martabat manusia. Namun dalam keadaan terpaksa sanksidapat dilakukan dengan carayang amathati-hatidan Ibnu Sina sangat membatasi pelaksanaan sanksi. ${ }^{7} \mathrm{Hal}$ ini mengindikasikan, pemberian sanksi dalam pendidikan diperbolehkan.

Hal senada juga dinyatakan oleh Şalih, terlepas dari dampak negatif yang ditimbulkannya, pemberian punishment (sanksi) tetap

4 Muhammad Shahbaz Arif dan Muhammad Shaban Rafi." Effects of Corporal Punishment and Psychological in Students' Learning and Behavior." Journal of Theory and Practice in Education, 3(2) (2007), h. 172.

5 JE Ormond. "Beyond Pavlop, Thorndike and Skinner': Other Early Behaviorist Theories," Pearson Education (2008), h. 1.

6 Muhammad Bin Ibrahim Al-Fawzan. Ibn Khaldūn wa Fikruhu al-Tarbawī. Saudi Arabia: King Sa'ud University, 2007. KSU Faculty Member Website (diakses pada tanggal 25 Mei 2014).

7 Mahmūd 'Abd al-Latif. Al - Fikr al-Tarbawī 'Inda Ibn Sīnā. Abhāth Wa Nazriyāt Tarbawiyah 50 (21/05/2014). 
diperlukan dengan beberapa alasan, yaitu : sanksi diberikan setelah semua cara lain yang digunakan tidak mampu merubah perilaku buruk siswa, pemberian sanksi harus hati-hati, karena jika tidak, dapat mempengaruhi jiwa dan kepribadian siswa dan pemberian sanksi disesuai dengan pelanggaran yang dilakukan. ${ }^{8}$

Pemberian sanksi dalam pendidikan menunjukkan bahwa pendidikan adalah pemaksaan dan bukan pemberian kebebasan kepada siswa. Menurut Anderson, ada dua pendekatan yang digunakan dalam pemaksaan, yaitu pemaksaan sebagai penekanan terhadap kemauan dan pemaksaan sebagai penegakan. ${ }^{9}$ Pernyataan tentang perlunya pemaksaan dalam pendidikan dengan memberikan sanksi bertentangan dengan teori yang dikemukakan oleh Carmelo Tropiano.

Hasil penelitian Tropiano menyimpulkan, pendidikan adalah proses pembebasan. Sehingga pendekatan pembelajaran model bank merupakan bentuk penindasan kepada siswa. Karena pada pendekatan pembelajaran model bank siswa harus mengikuti pembelajaran sesuai dengan ketentuan yang telah ditetapkan. Pada pendekatan pembelajaran model bank ada aktivitas yang membuat siswa merasa takut, yaitu berupa penolakan, intimidasi dan sanksi. ${ }^{10}$

Pemaksaan dalam pendidikan tidak sesuai dengan teori Carmelo Tropiano, tetapi teori Carmelo Tropiano ini sesuai dengan teori pendidikan humanis yang pertama kali dikemukakan oleh Carl Roger (1902-1987) yang menyatakan, adanya aktivitas pembelajaran yang ditentukan oleh guru merupakan bentuk penindasan kepada siswa. ${ }^{11}$ Menurut Rosyada, bentuk pembelajaran humanis merupakan bentuk aplikasi dari pedagogi konstruktivisme. ${ }^{12}$

8 Ali Abd al-Raḥīm Şāliḥ. "Al-'Iqāb al-Madrasī Al-Țarīqi Li al- Harb min Al-Madrasah.” Hamalāt Al-Tamaddun, al-Tarbiyah wa al-Ta'lim wa al-Bahthu al-'Amali (02/1/20080).

9 Scott A. Anderson,"The Enforcement Approaches To Coercion", Journal of Ethics \& Social Philosophy 5,1 (October, 2010), h. 1-6.

10 Carmelo Tropiano, "Paulo Freire Social Change and Teaching of Gothic Literature," College Quarterly 11,2 (Spring, 2008), h. 1- 10.

11 Carmelo Tropiano, "Paulo Freire. Social Change and Teaching of Gothic Literatur," 3.

12 Dede Rosyada. Pembelajaran PAIS Antara Behaviorisme dan Konstruktvisme (Jakarta : PT. Raja Grafindo Persada, 2009), h. 139-140. 
Teori Carmelo ini mendukung teori Paulo Freire (19211997) yang menyatakan bahwa pendidikan adalah sebuah proses pembebasan tanpa adanya tindakan guru yang manipulatif, baik berupa intimidasi, penolakan maupun sanksi. Teori Carmelo sesuai dengan pedagogi konstruktivisme ${ }^{13}$ dan bertentangan dengan pedagogi behaviorisme John B. Watson (1879-1958). ${ }^{14}$

Teori yang dikemukakan Carmelo Tropiano tidak sesuai dengan model pembelajaran behaviorisme yang pertama kali dikemukakan oleh John Broudus (1878-1958), ${ }^{15}$ pernyataan Amy Chua dan pernyataan Sol Stern, yang menyatakan perlu adanya pemaksaan dalam pendidikan.

Amy Chua menyatakan, pendidikan harus dilakukan dengan cara pemaksaan agar dihasilkan anak-anak yang sukses. ${ }^{16}$ Pemaksaan pendidikan dilakukan Amy Chua terhadap kedua anaknya. Meskipun kedua anak Amy Chua mempunyai karakter yang berbeda, keduanya sama-sama dapat meraih prestasi yang tinggi berkat adanya pendidikan dengan cara pemaksaan.

Demikian juga dengan hasil penelitian dari Sol Stern, di Cina dan Cuba: pendekatan pembelajaran bank membentuk siswa-siswa cerdas yang dapat dikontrol, disiplin, dan sarat dengan muatan pengetahuan dan menghasilkan banyak manager industri, insinyur dan ilmuwan. ${ }^{17} \mathrm{Hal}$ ini menunjukkan, hasil pembelajaran model bank, yang dikenal sebagai model pembelajaran dengan pemaksaan dan penindasan justru dapat menghasilkan siswa-siswa yang cerdas dan sukses.

Teori Amy Chua dan Sol Stern bertentangan dengan teori yang dikemukakan oleh Carmelo Tropiano tetapi sesuai dengan Teori behaviorisme. Menurut Rosyada, teori behaviorisme memandang,

13 William M. Reynolds Gloria E. Miller. Educational Psychology. Handbook of Psychology, Vol. 7 ( New Jersey : John Wiley \& Sons, Inc., 2003), h. 49-56.

14 W. David Pierce and Carl D. Cheney. Behavior Analysis and Learning. Third Edition (New Jersey : Lawrence Erlbaum Associates Publisher, 2004), h. 13-14.

15 Dede Rosyada. Pembelajaran PAIS Antara Behaviorisme dan Konstruktvisme (Jakarta: Raja Grafindo Persada, 2009), h. 131.

16 Amy Chua. Battle Hymn of The Tiger Mother (New York : Penguin Group, 2011), h. 11

17 Sol Stern, "Paedagogy of the oppressor. Another Reason Why The US end Schools are so awful': the ongoing of Brazilian Maxist Paulo Freire”, City Journal 19,2 (2009), h. 1. 
pengetahuan telah terstuktur rapi dan teratur sehingga siswa dihadapkan pada aturan-aturan yang jelas dan ditetapkan terlebih dahulu, kegagalan dalam pembelajaran dianggap sebagai kesalahan yang perlu dihukum. ${ }^{18}$

Berdasarkan hal tersebut, penulis menyimpulkan bahwa pendidikan adalah pemaksaan dan pemaksaan dalam pendidikan dapat dilakukan melalui pemberian sanksi yang mendidik dan manusiawi, yaitu sanksi yang dapat mengakibatkan efek jera, namun tidak menyakiti dan tidak melukai siswa.

\section{B. LANDASAN TEORI}

\section{Prestasi Belajar Siswa}

Prestasi belajar menjadi tolok ukur dalam suatu proses pembelajaran. Keberhasilan atau kegagalan suatu proses pembelajaran dapat dilihat melalaui prestasi belajar yang diperoleh siswa, sehingga prestasi belajar merupakan hasil pengukuran kemampuan peserta didik setelah mengikuti proses pembelajaran dalam periode tertentu.

Seifort dan Sutton mendefinisikan belajar secara umum sebagai perubahan yang relatif permanen dalam perilaku, keterampilan, pengetahuan, atau sikap yang dihasilkan dari pengalaman psikologis atau sosial yang dapat diidentifikasi. ${ }^{19}$ Hal ini berarti, banyak hal yang harus dilakukan dalam pembelajaran. Karena dalam pembelajaran tidak hanya mencerdaskan aspek kognitif siswa saja, tetapi juga mencerdaskan aspek lain yang terkait dalam diri siswa, yaitu ranah kognitif, ranah afektif dan ranah psikomotorik.

Banyak faktor yang mempengaruhi prestasi belajar, baik berupa faktor internal maupun faktor eksternal. Faktor yang mempengaruhi prestasi belajar menurut Huitt dan lain-lain, dapat berupa variabel yang berasal dari rumah dan sekolah,

18 Dede Rosyada, Pembelajaran PAIS antara Behaviorisme dan Konstructivisme, h. 133.

19 Kelvin Seifert and Rosemary Sutton. Educational Psychology. Second Edition (Zurich, Switzerland : the Jacobs Foundation, 2009), h. 20. 
variabel yang berasal dari rumah dapat berupa sosial ekonomi keluarga, keadaan lingkungan rumah dan keterlibatan orang tua. Variabel yang berasal dari sekolah berupa input dan prosesproses yang terjadi di kelas. Input di kelas berupa karakteristik guru dan karakteristik siswa. Proses-proses yang terjadi di kelas berupa strategi belajar mengajar, perilaku guru, perilaku siswa dan proses belajar mengajar. ${ }^{20}$

Ranah prestasi belajar siswa, yaitu ranah kognitif, afektif dan psikomotorik harus dikembangkan secara seimbang, sehingga untuk mencapai hasil pendidikan secara optimal dan komprehensif, menurut Neuman dan Bruce, pendidik tidak bisa hanya fokus pada ranah kognitif saja, tetapi perlu untuk menggabungkan semua ranah dalam pembelajaran. ${ }^{21}$ Ketiga ranah ini harus tersentuh, karena ketiganya saling berhubungan satu sama lain. ${ }^{22}$

\section{Paradigma Pemaksaan dan Pembebasan dalam Pendidikan}

Kebebasan secara umum berarti tidak ada paksaan. Baik paksaan secara fisik, paksaan moral maupun paksaan psikologis. Namun menurut Madani, kebebasan adalah kemampuan seseorang dalam melakukan pengendalian diri. ${ }^{23}$ Sehingga kebebasan manusia dalam Islam tidak hanya untuk kepentingan kemanusiaan, tetapi juga bernuansa teosentris, sebagai bentuk pertanggungjawaban dan pengendalian diri.

a. Pemaksaan dan Pembebasan dalam Pendidikan

Kebebasan menurut Al Maududi merupakan hak yang diberikan Allah pada tiap individu, sehingga manusia

20 William G. Huitt dan lain-lain. "Improving Student Achievement 1: A Systems-based Synthesis of Research Related to Improving Students' Academic Performance.”. Paper presented at the 3rd International City Break Conference sponsored by the Athens Institute for Education and Research (ATINER), (October 16-19, 2009), h. 2.

21 Karen Neuman Allen and Bruce D. Friedman. "Affective learning: A Taxonomy for Teaching Social Work Values". Journal of Social Work Values and Ethics 7, 2 (Fall 2010), h. 10.

22 Mary J. Pickard. “The New Bloom's Taxonomy: An Overview for Family and Consumer Sciences." Journal of Family and Consumer Sciences Education. 25,1,(Spring/Summer 2007), h. 47.

23 Abdul Hai Madani, "Freedom and Its Concept in Islam." International Conference on Humanities, Historical and Social Sciences 17,2 (Singapore, 2011), h. 116. 
sebagai makhluk individu memiliki hak untuk memperoleh kebebasan. ${ }^{24} \mathrm{Hal}$ ini menunjukkan, pada hakikatnya manusia merupakan makhluk multidimensi yang mengetahui tentang kebebasannya untuk melakukan atau meninggalkan suatu perbuatan. Hal senada dinyatakan oleh Bishop. Kebebasan Menurut Bishop merupakan sesuatu yang melekat sejak manusia dilahirkan. ${ }^{25}$ Selanjutnya Shari'ati (1933-1977) mendefinisikan manusia sebagai makhluk berfikir, memiliki kehendak bebas, makhluk kreatif, mempunyai cita-cita, merindukan sesuatu yang ideal dan merupakan makhluk moral. ${ }^{26}$ Dengan demikian, pada fitrahnya manusia adalah mahkluk bebas dan berhak mendapatkan kebebasan.

Menurut Imarah, dalam pandangan Islam, kebebasan manusia merupakan hal yang sangat penting, karena hanya dengan kebebasan, manusia dapat mempunyai arti dalam hidupnya. ${ }^{27}$ Kebebasan manusia juga terjadi dalam pendidikan.

Menurut Freire (1921-1997), pendidikan merupakan praktik kebebasan dan ini bertentangan dengan pendidikan sebagai praktik dominasi dari pendidik. ${ }^{28}$ Sehingga dalam pembebasan pendidikan, siswa diberikan kebebasan sepenuhnya untuk menentukan proses pembelajaran. Guru hanya merupakan fasilitator dan pelaksanaan pembelajaran sepenuhnya ditentukan oleh siswa. Hal ini berbeda dengan makna kebebasan dalam Islam.

Kebebasan dalam Islam, menurut Madani, ibarat kekang yang diberikan pada kuda yang sedang berlari dan tidak ada ayat dalam Al-Qur'an yang benar-benar

24 Abu A'la Al Maududi. Human Rights in Islam (London: The Islamic Foundation, 1980), 19.

25 Philip Schuyler Bishop, “Three Theories of Individualism”. Thesis. University of South Florida Scholar Common (2007), h. 71.

26 Ali Shari'ati, Marxism and other Western Fallacies. Translated by R. Campbell. (Berkeley, Calif.: Mizan Press, 1980), h. 14-16.

27 Muhammad 'Imarah. al-Islām wa Huqūqu al-Insān (Beirut: 'Alim al- Ma'rifah, 1990), 13

28 Paulo Freire, Pedagogy of the Oppressed Translated by Myra Bergman Ramos (New York : The Continuum International Publishing Group Inc, 2005 ), h. 79. 
menyatakan tentang kebebasan pada manusia, kecuali ayat yang berhubungan dengan kebebasan pada perbudakan. Ini berarti, dalam Islam kebebasan selalu dikaitkan dengan keadilan. ${ }^{29}$ sehingga pada prinsipnya dalam pandangan Islam, manusia adalah makhluk bebas, namun kebebasan manusia bukanlah kebebasan tanpa batas, tetapi kebebasan yang tetap pada kendali yang telah ditentukan oleh Allah SWT.

Naisaban menyatakan, menurut Carl Roger (19021987), setiap orang mempunyai kebutuhan akan anggapan positif, yaitu anggapan yang bernilai bagi dirinya sendiri. Carl Roger juga menyatakan bahwa konsep diri manusia bersifat tersirat dan terpadu, dia terdiri dari apa yang diinginkan, dicita-citakan atau apa yang seharusnya dianggap demikian. ${ }^{30}$

Azra menyatakan, manusia dalam pandangan Islam adalah makhluk rasional dan sekaligus mempunyai hawa nafsu kebinatangan. Sehingga manusia bisa menjadi pribadi yang dekat dengan Tuhan, tetapi jika manusia tidak mampu mengendalikan nafsu ke-binatangannya bisa menjadi makhluk yang paling hina. ${ }^{31}$ Oleh karena itu perlu adanya pembatasan terhadap kebebasan, agar manusia terhindar dari perbuatan jahat. Salah satu cara membatasi kebebasan melalui pemaksaan.

Anderson menyatakan, Ada dua pendekatan yang digunakan dalam pemaksaan, yaitu pemaksaan sebagai penekanan terhadap kemauan dan pemaksaan (punishment) sebagai penegakan. ${ }^{32}$ Menurut Suseno pada prinsipnya ada tiga cara membatasi kebebasan manusia, yaitu melalui

29 Abdul Hai Madani, "Freedom and Its Concept in Islam." International Conference on Humanities, Historical and Social Sciences 17,2 (Singapore, 2011), h. 116-117.

30 Ladislaus Naisaban, Para Psikolog Terkemuka di Dunia (Jakarta :PT. Gramedia Widiasarana Indonesia, 2004), h.344.

31 Azyumardi Azra. Pendidikan Islam : Tradisi dan Modernisasi Menuju Milenium Baru (Ciputat : PT. Logos Wacana Ilmu,1999), h. 7.

32 Scott A. Anderson,"The Enforcement Approaches To Coercion", Journal of Ethics \& Social Philosophy 5,1 (October, 2010), h. 1-6. 
pemaksaan atau pemerkosaan fisik, melalui tekanan atau manipulasi fisik dan melalui pewajiban dan larangan. ${ }^{33}$

Dengan demikian salah satu cara pembatasan pembebasan adalah melalui pemaksaan, sehingga pendidikan bukan merupakan pembebasan tapipemaksaan. Dari uraian tersebut menimbulkan pertanyataan tentang pendidikan, yaitu pendidikan merupakan pembebasan atau pendidikan merupakan pemaksaan.

Pemaksaan seperti dinyatakan oleh Bratton, dapat dilakukan dengan dua cara yaitu melalui pencegahan dan membuat mereka tunduk. ${ }^{34}$ Botas menyatakan, pemaksaan pendidikan di masa lalu merupakan gaya pedagogy utama dalam mengajar dan pemaksaan dalam pendidikan dapat dilakukan guru dengan cara memberitahukan kepada siswa tentang bagaimana menghasilkan suatu pekerjaan dan apa yang tidak boleh dilaksanakan ketika menghasilkan pekerjaan tersebut. ${ }^{35}$

Hal ini mengindikasikan bahwa pemaksaan dalam pendidikan berupa adanya aturan yang harus dilakukan siswa dalam pelaksanaan proses belajar mengajar. Karena siswa merupakan bagian dari masyarakat, sehingga dengan adanya aturan, dapat menciptakan kehidupan yang harmonis dalam masyarakat.

Pemaksaan pendidikan dilakukan oleh Chua, yaitu salah satu orang tua di China. Menurut Chua, untuk menghasilkan anak-anak yang sukses, pendidikan harus dilakukan dengan pemaksaan. Chua telah berhasil menjadikan anak-anaknya sukses dalam pendidikan dengan melakukan pemaksaan pendidikan. Chua menuntut nilai sempurna dari anak-anaknya, memarahi anak-anaknya jika tidak memperoleh nilai sempurna dan

33 Franz Magniz Suseso, Etika Dasar, Masalah-masalah pokok Filsafat Moral (Jakarta : Kanisius, 1989), h. 37.

34 Patrick C. Bratton, “When is Coercion Succesfull?," h. 101.

35 Paulo Charles Pimental Botas, “Sudents' Perception of Teachers'Pedagogical Styles in Higher Education”, Research Paper (2006), h. 21. 
melarang anak-anaknya melakukan aktivitas, kecuali atas persetujuannya. ${ }^{36} \mathrm{Hal}$ ini menunjukkan, pemaksaan dapat memberikan dampak positif dalam pendidikan.

Pemaksaan dalam pendidikan dimaksudkan sebagai bentuk pembiasaan. Menurut Pierce and Cheney, pembiasaan (habituasi) adalah proses perilaku yang telah terjadi karena sejarah filogenetik, hal ini dapat terjadi melalui pengulangan suatu kejadian. Secara fisiologi pembiasaan atau habituasi bisa terjadi, karena telah adanya pembangunan busur refleks pada diri seseorang. ${ }^{37}$

Dengan demikian pemaksaan dalam pendidikan merupakan suatu cara pembatasan kebebasan siswa melalui pemberian sanksi terhadap pelanggaran yang dilakukan, memberitahukan tentang apa yanng boleh dan tidak boleh dilakukan melalui kewajiban dan larangan dan adanya kontrol yang ketat terhadap aktivitas siswa.

b. Pembebasan dalam Pendidikan

Nelson mendefinisikan pendidikan sebagai aktivitas yang dilakukan untuk pengembangan dan kebebasan akademik, ${ }^{38}$ hal ini sesuai dengan Tropiano yang menyatakan bahwa pendidikan merupakan pembebasan. ${ }^{39}$ hal yang sama juga dinyatakan oleh Kadenyi dan Kariuki yang menyatakan bahwa pendidikan harus membebaskan manusia dari situasi yang membelenggu dan meng-hambat pengembangan dirinya. ${ }^{40}$

Arnold Dodge menyatakan, dalam proses pembelajaran

36 Amy Chua, "Why Chinese Mother Are Superior". The Wall Street Journal on Line: The Saturday Essay (January 8, 2011), h. 1-8.

37 W. David Pierce and Carl D Cheney.Behavioral Analysis and Learning, Third Edition (London : Lawrence Erlbum Acossiates Publisher, 2004), h. 76.

38 Jack L. Nelson. "Academic Freedom, Institutional Integrity, and Teacher Education." Teacher Education Quarterly (Winter, 2003), h. 63.

39 Carmelo Tropiano, "Paulo Freire, Social Change, and The Teaching of Gothic". College Quarterly 11,2 (2009), h. 3.

40 Misia Kadenyi and Michael Kariuki," Rethinking Education for Liberation and Self-Reliance : An Examination of Nyere's and Plato's Paradigm", International Journal of Curriculum and Instruction 1,1 (April, 2011), 17. 
siswa harus diberikan kebebasan ${ }^{41} \mathrm{Hal}$ ini sesuai dengan pendapat Osman yang menyatakan tentang pendidikan yang membebaskan. Pendidikan yang membebaskan menurut Osman, dibutuhkan agar siswa menjadi manusia seutuhnya yang memungkinkan siswa menjadi kritis, mampu bertindak dan mengubah keadaan. ${ }^{42}$

Dengan adanya pendidikan yang membebaskan, guru memberikan kesempatan kepada siswa untuk berfikir secara kritis dan mendorong siswa menjadikreatif. Sehingga siswa tumbuh menjadi individu yang bertanggung jawab. Hal ini sesuai dengan pendapat Pring.

Ciri-ciri pendidikan membebaskan seperti yang dinyatakan oleh Pring adalah: mengembangkan kecerdasan untuk meningkatkan daya pemikiran dan pemahaman, perkembangan intelektual tidak hanya didasarkan pada pengetahuan praktis, tetapi juga filosofis, siswa belajar didasarkan pada ketertarikan dan siswa mempunyai tanggung jawab dalam belajar. ${ }^{43}$

Sedangkan pembebasan pendidikan menurut Hruby adalah sebuah model pendidikan di mana masing-masing orangdiberikebebasan menentukan tujuan pembelajarannya sesuai dengan kemuannya sendiri. ${ }^{44}$ Pembebasan pendidikan menurut Ohan merupakan pendidikan yang memberikan dampak kebebasaan kepada seseorang untuk melakukan apa yang diinginkan. ${ }^{45} \mathrm{Hal}$ ini tidak sesuai dengan pembebasan pendidikan menurut Islam. Pembebasan pendidikan dalam perspekif Islam adalah pendidikan yang sesuai dengan tujuan pendidikan dalam Islam.

41 Arnold Dodge. "Heuristic and NCLB Standardize Test' : A Convenience Lie", International Journal of Progressive Education 5,2, (2009), h. 13, Retviered From Erick.

42 Ahmad A. Osman, "Freedom in Teaching and Learning". International Journal of Humanities and Social Science 3,2 (Spesial Issue, January 2013), h. 147.

43 Richard Pring. Philosophy of Education (New York : Bookends, Ltd, Royston, 2005), h. 49-51.

44 M. Hruby, "Freedom in Adult Education". Journal on Efficiency and Responsibility in Education and Science 1,2 (2008), h. 14.

45 Christopher Ohan, “An Incompatible Method: The Western Liberal Arts Educational Model In Kuwait and The Arab Gulf Region". Journal of Educational and Social Research 2,3 (September, 2012), h. 43. 
Jabr menyatakan bahwa tujuan pendidikan dalam Islam terdiri dari empat tingkatan, pertama, tujuan pada tingkat penghambaan manusia pada Allah SWT, kedua: pada tingkat individu, untuk menciptakan karakter Islam, ketiga: Pembangunan komunitas muslim atau nationbuilding dan keempat: tujuan yang berkisar mencapai manfaat agama dan sekuler ${ }^{46}$. Ini mengindikasikan bahwa tujuan pendidikan dalam Islam bersifat menyangkut seluruh aspek hidup manusia. baik berupa hubungan antara manusia dengan sang Khāliq (Allah SWT) maupun hubungan manusia dengan sesamanya.

Menurut Al-Atas, pendidikan adalah proses menanamkan sesuatu ke dalam diri sesorang, dengan tujuan akhir menjadi manusia sempurna (Insān Kāmil). ${ }^{47}$ Insan kamil, bisa diartikan sebagai manusia yang mengabdikan diri hanya beribadah kepada Allah. Hal ini sesuai dengan tujuan Allah menciptakan makhlukNya. Sedangkan Muthahhari (1920-1979) mendefinisikan Insān Kāmil sebagai insan yang memiliki keseimbangan seluruh nilai-nilai insaninya. ${ }^{48} \mathrm{Hal}$ ini berarti, Insān Kāmil bukanlah manusia taat, saleh, bijaksana dan penuh kasih. Tetapi Insān Kāmil adalah manusia yang semua nilai-nilai kemanusiaannya tumbuh dan berkembang secara harmoni dan seimbang. ${ }^{49}$ Sehingga dapat disimpulkan, bahwa pendidikan merupakan usaha sadar manusia dengan tujuan mengembangkan seluruh potensi dasar manusia, agar tercipta hubungan yang baik antara manusia dengan Sang Khāliq dan manusia dengan sesamanya.

Pendidikan yang membebaskan bukanlah pendidikan dengan memberikan kebebasan sepenuhnya kepada siswa,

46 Muhammad Bn Sālam Bn 'Ali Jābir. "Ahdāf al-Tarbīyah al-Islamīyah wa Maqāsidihā." Maqūlāt Muta'alliqah 355117 (12 Juli 2006) www.alukah.net (diakses pada tanggal 13 Juni 2014).

47 Syed Muhammad Naquib Al-Atas. "Understanding the Concept of Education in Islam." Harakah Daily (9 March, 2014).

48 Murțādā Muțțah>rī. Insān-e Kāmil. Isfāhān : Markaze Tahqiqāt Rayāne-i. www.Ghaemiyeh. com, tt : 12 (diakses pada tanggal 3 mei 2014). Lihat juga Murțādā Muțțah>rī. Yād-e Dāshtāhā-e Ustād Muțțāhārī, Jild Aval, Harf Alef. Tehrān va Qum : Sadrā, 1978, h. 282 - 307.

49 Murtadha Muthahhari. "Insān-e Kāmil”. Ruznāmeh Risālat, 6135 (2/12/86), h. 17. 
tetapi pendidikan yang membebaskan adalah pendidikan yang mendorongnya untuk mendekati tuhan dan mampu mengembangkan semua potensi yang dimilikinya. Selain itu, tujuan dari pembebasan pendidikan menurut A. Storss dan Inderbitzin adalah untuk menolong siswa agar tumbuh menjadi individu yang dengan sengaja dalam melakukan pembelajaran, kehidupan dan menjadi individu yang bertanggung jawab. ${ }^{50}$

Berdasarkan uraian yang telah dipaparkan, semua sepakat bahwa pendidikan merupakan proses pembebasan, namun terdapat perbedaan dalam memberikan arti kebebasan. Sebagian berpendapat bahwa pendidikan dengan pembebasan adalah peserta didik diberikan kebebasan dalam menentukan berlangsungnya proses pendidikan. Tetapi sebagian lain berpendapat, pendidikan pembebasan adalah pendidikan dengan memberikan kesempatan kebebasan kepada siswa untuk mengembangkan potensi yang dimilikinya agar menjadi manusia yang bertanggung jawab.

\section{METODOLOGI PENELITIAN}

Penelitian ini dilakukan di Pondok Pesantren Salafi Terpadu (PPST) Ar-Risalah Lirboyo Jawa Timur dengan jumlah sample sebanyak 65 orang. Penelitian ini menggunakan metode penelitian campuran (Mixed Method).

Validitas data digunakan baik secara kualitatif maupun kuantitatif. Secara kualitatif data divalidasi dengan menggunakan triangulasi dan secara kuantitatif data divalidasi dengan menggunakan koefisien korelasi spearment brown dan koefisien korelasi point biserial. Reliabilitas data dilakukan secara kuantitatif dengan menggunakan alpha cronbach dan KR 21. Analisis data secara kuantitatif dengan menghitung koefisien korelasi ( $\mathrm{r}$ ) dan nilai kontribusi variabel sanksi dengan prestasi belajar $\left(r^{2}\right)$.

50 Debbie A. Storss and Michelle Inderbitzin, "Imagining a Liberal Education: Criticcally the Learning Process Through Simulation”, Journal of Transformative Eduation 4 (2006), h. 186. 
Hipotesis dari penelitian ini adalah : terdapat hubungan positif dan signifikans antara pemberian sanksi dengan prestasi belajar siswa. Atau secara statistic hipotesis ini dapat dituliskan sebagai berikut :

Ho: $r x y=0$

$\mathrm{H} 1: \mathrm{rxy} \neq 0$

\section{HASIL DAN PEMBAHASAN}

\section{Korelasi dan Kontribusi Pemberian Sanksi Terhadap Pemaksaan Dalam Pembelajaran}

Kegiatan harian PPST Ar-Risalah tidak terlepas dari pelaksanaan tata tertib yang telah ditetapkan oleh pondok pesantren. Pelanggaran terhadap tata tertib akan dikenakan sanksi baik berupa sanksi fisik maupun sanksi non fisik sesuai dengan ketentuan yang telah ditetapkan.

Pelaksanaan tata tertib bertujuan untuk meningkatkan prestasi belajar santri. Pelaksanaan penegakan tata tertib di PPST ini dilakukan melalui pengontrolan ketat terhadap semua aktivitas santri, bahkan sikap pondok tidak segan-segan memberikan sanksi (punishment) bagi setiap pelanggaran yang terjadi dan santri dianggap melakukan pelanggaran terhadap tata tertib apabila santri tidak melaksanakan kewajiban atau santri melakukan kegiatan larangan.

Menurut Şālih tujuan pemberian sanksi pada pendidikan di sekolah adalah untuk mengontrol perilaku siswa, karena sekolah merupakan elemen pendidikan yang berfungsi membangun semua aspek manusia, baik aspek mental, emosional maupun fisik. ${ }^{51}$

Pemberian sanksi di PPST Ar-Risalah bervariasi mulai dari berupa teguran, denda berupa uang sampai kepada sanksi fisik. $^{52}$ Selanjutnya Straus mengartikan Corporal punishment

51 Ali Abdu Al-Raḥīm Şālih. "Al-'Iqāb Al-Madrasī Al-Țarīqi Lil Harbi Min Al-Madrasati." Hamalāt Al-Tamdun, Al-Tarbiyah wa Al-Ta'lìm Wa Al-Bahthu Al-'Amali (02/1/20080). 2013.

52 Wawancara dengan Ustadh MA, PPST Ar-Risalah, Lirboyo, Jawa Timur, tanggal 9 Oktober 
atau sanksi fisik sebagai penggunaan kekuatan fisik yang menimbulkan pengalaman rasa sakit pada anak, tetapi tidak sampai melukai dengan tujuan sebagai mengontrol terhadap tingkah laku anak. ${ }^{53}$

Dari uraian tersebut dapat disimpulkan bahwa setiap pelanggaran terhadap tata tertib di PPST Ar-Risalah dikenakan sanksi, baik sanksi fisik maupun sanksi non fisik, namun sanksi tersebut tidak sampai melukai santri. Karena sanksi yang diberikan bertujuan hanya sebagai kontrol terhadap perilaku santri.

Adanya pemberian sanksi menunjukkan bahwa pendidikan di PPST Ar-Risalah ini berbentuk pemaksaan. Pemaksaan dalam pendidikan dimaksudkan untuk meningkatkan prestasi siswa, karena semua anak meskipun mempunyai perbedaan secara individual tetapi mereka mempunyai kesamaan, yaitu anak bisa berhasil jika melakukan kerja keras.

Sesuai dengan pernyataan Chua, bahwa pada dasarnya semua anak bisa dijadikan sukses dan untuk memperoleh kesuksesan harus melakukan kerja keras, masalahnya anakanak biasanya tidak mau bekerja, sehingga disinilah peran orang tua dalam mengarahkannya. ${ }^{54}$ Demikian juga dengan pernyataan Muțțahari, meskipun punishment bukan merupakan faktor pendorong pengembangan potensi anak, namun pada masyarakat kosmopolitan, punishment tetap diperlukan untuk mencegah sikap membandel atau vandalisme. ${ }^{55}$

Adanya sanksi bertujuan untuk memberikan santri pembiasaan dalam bersikap baik. Sesuai pernyataan Pierce and Cheney bahwa pembiasaan (habituasi) adalah proses perilaku yang telah terjadi karena sejarah filogenetik, hal ini dapat terjadi melalui pengulangan suatu kejadian. Secara fisiologi pembiasaan atau habituasi bisa terjadi karena telah adanya

53 Murray A. Straus. "Corporal Punishment and Primary Presentation of Physical Abuse," Child Abuse \& Neglect 24,9 (2000), h. 10.

54 Amy Chua. Battle Hymn of The Tiger Mother (New York : Penguin Group, 2011), h. 35-36.

55 Murțāda Muțțaharī. al-Tarbiyah wa al-Ta'lìm fi al-Islām. Beirut:Dār al- Hadi,tt. www.alameeniq.com/book/akhlaq/29/f.htm (diakses pada tanggal 5 Mei 2014). 
pembangunan busur refleks pada diri seseorang. ${ }^{56}$

Pembiasaan dalam pendidikan mempunyai peran yang sangat penting. Pembiasaan pendidikan sesuai dengan teori behaviorisme Ivan Pavlop (1849 - 1936), yaitu seluruh perilaku manusia adalah hasil dari belajar. ${ }^{57}$ Menurut Raygor pembelajaran melalui pemaksaan merupakan bentuk pembelajaran yang paling sederhana dan agar pemaksaan yang diinginkan berhasil, maka memerlukan stimulus secara berulang-ulang. ${ }^{58}$

Pemberian sanksi dan pemaksaan berdasarkan hasil penelitian di PPST Ar-Risalah mempunyai keeratan hubungan yang cukup tinggi yaitu sebesar 0.779. Ini berarti bahwa punishment dalam pendidikan berkaitan erat dengan pemaksaan, semakin tinggi tingkat punishment maka semakin tinggi pemaksaan.

Tingkat signifikansi keeratan hubungan ( $\mathrm{r}$ ) antara pemaksaan dan punishment dapat terlihat pada tabel 1 . Adapun kontribusi $\left(\mathrm{r}^{2}\right)$ pemberian sanksi terhadap pemaksaan sebesar 60.6841. Hal ini menunjukkan bahwa pemaksaan dalam pendidikan ditentukan dengan pemberian sanksi sebear 60.6841 dan selebihnya yaitu sebesar 39.3159 ditentukan oleh variable lain.

Tabel 1. ANAVA Hubungan antara Punishment (X) dengan Pemaksaan (Y)

\begin{tabular}{|c|c|c|c|c|c|c|}
\hline $\begin{array}{c}\text { Sumber } \\
\text { variasi }\end{array}$ & $\mathrm{JK}$ & $\mathrm{Db}$ & $\mathrm{RJK}$ & $\mathrm{F}_{\mathrm{h}}$ & $\mathrm{F}_{\mathrm{t}(0.05 ; 1,62)}$ & $\mathrm{F}_{\mathrm{t}(0.01 ; 1,62)}$ \\
\hline Regresi & 8896.981 & 1 & 8896.981 & \multirow{2}{*}{95.515} & 3.995 & 7.100 \\
\cline { 1 - 5 } Sisa & 5775.125 & 62 & 93.147 & & & \\
\hline Total & 14672.109 & 63 & & & & \\
\hline
\end{tabular}

Dari tabel 1 terlihat bahwa nilai $\mathrm{F}_{\text {hitung }}=95.515>\mathrm{F}_{\text {table(1,36:0.01) }}$ $=7.100$. Hal ini berarti, hipotesis penelitian yang menyatakan

56 W. David Pierce and Carl D Cheney.Behavioral Analysis and Learning, Third Edition (London : Lawrence Erlbum Acossiates Publisher, 2004), h. 76.

57 Soejidjo Notoatmodjo, Ilmu Perilaku Kesehatan (Jakarta : Rineka Cipta, 2010), h. 5.

58 Robin Raygor. The Science of Psychology (New York : Mc-Graw hill University, 2005), h. 237. 
bahwa terdapat hubungan positif yang signifikans antara pemberian sanksi dengan pemaksaan terbukti. Dengan adanya sanksi terhadap santri, maka telah terjadi pemaksaan dalam pendidikan. Semakin tinggi tingkat pemberian sanksi, maka semakin tinggi juga tingkat pemaksaan.

Pemberian sanksi diberikan kepada santri ketika santri melakukan pelanggaran terhadap tata tertib yang telah ditetapkan oleh pondok. Kegiatan pendidikan di Pondok pesantren ini dilakukan sesuai dengan jadwal yang telah ditentukan, sehingga model pendidikan di tempat ini adalah model pedagogy progresivisme yang merupakan bentuk kebalikan dari pedagogy Constructivisme. Hal ini sesuai dengan pernyataan Hassad bahwa Perbedaan utama antara kedua pendekatan ini adalah : pedagogy behaviorisme berpusat di sekitar transmisi pengetahuan dari instruktur kepada siswa (siswa pasif dan pendekatan top-down atau instruktur berpusat), sedangkan pedagogy konstruktivisme difokuskan pada pembangunan pengetahuan oleh siswa (siswa aktif dan pendekatan bottom-up atau berpusat pada siswa). ${ }^{59}$

Dalam pelaksanaan kegiatan harian di pondok pesantren ini dilakukan pengontrolan yang sangat ketat. Setiap siswa diwajibkan untuk mentaati peraturan yang telah ditetapkan dan jika terjadi pelanggaran, maka akan diberikan sanksi. Menurut Ellias dalam pembelajaran dengan Behaviorisme adanya kontrol yang sangat kuat terhadap tujuan.

Materi, lingkungan dan pegukuran hasil belajar. Sehingga teori ini banyak dikritik dan dianggap sebagai pedagogi penindasan, karena proses pembelajaran ini merupakan model pembelajaran yang tidak menghargai kondisi anak, keinginan anak dan minat dari pembelajar. Pedagogi ini menurut para tokoh humanis secara psikologis menindas siswa-siswa, karena menghambat kreativitas dan pengembangan potensi anak. ${ }^{60}$

59 Rossi A. Hassad, Constructivist and Behaviorist Approaches: Development and Initial Evaluation of a Teaching Practice Scale for Introductory Statistics at the College Level," Advancing Education in Quantitative Literacy 4,2 (2011), h. 3.

60 John L. Ellias, Paulo Freire, Pedagogue of Liberation (Florida : Kriegar Publishing Company, 1994), h. 123. 
Adapun bentuk sanksiyang diberikan terhadap pelanggaran tata tertib dapat dilihat pada tabel 2.

Tabel 2. Sanksi terhadap pelanggaran Tata Tertib.

\begin{tabular}{|c|l|l|}
\hline No & \multicolumn{1}{|c|}{ Bentuk Pelanggaran } & \multicolumn{1}{c|}{ Sanksi Yang Diberikan } \\
\hline 1 & Tidak masuk sekolah & Push up \\
\hline 2 & Terlambat masuk sekolah & Lari keliling lapangan \\
\hline 3 & Membuat kegaduhan & berdiri di sudut ruangan \\
\hline 4 & Pakaian tidak rapih & Push up/lari keliling lapangan \\
\hline 5 & Ghosob & Disiram air / berdiri di sudut ruangan \\
\hline 6 & Mengantuk & Disiram air / berdiri di sudut ruangan \\
\hline 7 & Berkelahi & Berdiri \\
\hline 8 & Menyontek & Disiram air / berdiri di sudut ruangan \\
\hline 9 & Ngobrol pada jam pelajaran & berdiri di sudut ruangan \\
\hline
\end{tabular}

Pada tabel 2. terlihat, punishment yang paling sering diberikan kepada santri adalah berdiri di sudut ruangan selama berjam-jam. Hal ini menunjukkan sebagian besar punishment adalah berupa sanksi fisik atau corporal punishment.

\section{Korelasi dan kontribusi Pemberian Sanksi terhadap Prestasi Belajar Siswa}

PPST Ar-Risalah berusaha untuk mencerdaskan ranah kognitif santri, baik berupa kemampuan menghapal, memahami dan menerapkan materi yang telah diajarkan oleh pihak pondok. Namun untuk aspek analisis, sintesis dan evaluasi belum tersentuh. ${ }^{61} \mathrm{Hal}$ ini menunjukkan bahwa pembelajaran di PPST Ar-Risalah belum memenuhi ranah yang seharusnya dicapai untuk memperoleh pembelajaran secara komprehensif.

Dari penelitian diperoleh hasil, nilai koefisien korelasi antara punishment dan hasil belajar sebesar 0.630 dan koefisien determinasi sebesar $0.396 .{ }^{62}$ hal ini menunjukkan bahwa punishment mempunyai korelasi yang cukup tinggi terhadap prestasi belajar.

61 Observasi di PPST Ar-Ridalah pada tanggal 9 dan 10 Oktober 2013.

62 Hasil perhitungan dengan SPSS versi 18 
Adapun kontribusi $\left(\mathrm{r}^{2}\right)$ pemberian sanksi terhadap prestasi belajar sebesar 39.60. hal ini berarti bahwa prestasi belajar 39.36 persen ditentukan oleh variable pemberian sanksi dan selebihnya yaitu 63.64 tingkat prestasi belajar ditentukan oleh variabel lain.

Sesuai dengan pernyataan Amy Chua bahwa pendidikan harus dilakukan dengan cara pemaksaan agar dihasilkan anakanak yang sukses. ${ }^{63}$ Demikian juga dengan hasil penelitian dari Sol Stern, di Cina dan Cuba, yang berhasil melakukan pendidikan melalui pemaksaan. ${ }^{64} \mathrm{Hal}$ ini menunjukkan, hasil pembelajaran dengan pemaksaan dan penindasan justru dapat menghasilkan siswa-siswa yang cerdas dan sukses.

\section{E. KESIMPULAN}

Penelitian ini membuktikan, pendidikan melalui pemaksaan dapat dilakukan melalui pemberian sanksi, semakin tinggi pemberian sanksi maka semakin tinggi tingkat pemaksaan

Pemberian sanksi yang bijaksana adalah sanksi yang diberikan secara hati-hati, tidak mengakibatkan penderitaan pada santri dan sanksi disesuaikan dengan kesalahan yang dilakukan.

Sanksi tersebut berupa berdiri di sudut ruangan, push up, scott jump, berlari mengeliling lapangan, diguyur air dan jalan sambil berjongkok. Sanksi non fisik berupa dipermalukan, dimarahi dan denda berupa uang.

Hasil penelitian menunjukkan, Pemberian sanksi dan pemaksaan mempunyai keeratan hubungan yang cukup tinggi yaitu sebesar 0.779. dan kontribusi $\left(\mathrm{r}^{2}\right)$ sebesar 60.6841, sedangkan nilai koefisien korelasi antara punishment dan hasil belajar sebesar 0.630 dan koefisien determinasi sebesar 0.396

63 Amy Chua. Battle Hymn of The Tiger Mother (New York : Penguin Group, 2011),11

64 Sol Stern, "Paedagogy of the oppressor. Another Reason Why The US end Schools are so awful': the ongoing of Brazilian Maxist Paulo Freire", City Journal 19,2 (2009) : 1. 


\section{DAFTAR PUSTAKA}

Al-Atas, Syed Muhammad Naquib. "Understanding the Concept of Education in Islam." Harakah Daily (9 March, 2014).

Allen, Karen Neuman and Friedman, Bruce D. "Affective learning: A Taxonomy for Teaching Social Work Values". Journal of Social Work Values and Ethics 7, 2 (Fall 2010) :1-15.

Al-Fawzan, Muhammad Bin Ibrahim . Ibn Khaldūn wa Fikruhu alTarbawi. Saudi Arabia: King Sa'ud University, 2007. KSU Faculty Member Website (diakses pada tanggal 25 Mei 2014).

Al Maududi, Abu A'la. Human Rights in Islam (London : The Islamic Foundation, 1980), 1-20.

Anderson, Scott A."The Enforcement Approaches To Coercion", Journal of Ethics \& Social Philosophy 5,1 (October, 2010): $1-10$.

Arif, Muhammad Shahbaz dan Rafi, Muhammad Shaban." Effects of Corporal Punishment and Psychological in Students' Learning and Behavior." Journal of Theory and Practice in Education, 3(2) (2007): 170-179.

Azyumardi Azra. Pendidikan Islam : Tradisi dan Modernisasi Menuju Milenium Baru (Ciputat : PT. Logos Wacana Ilmu,1999), 7

Bishop, Philip Schuyler. "Three Theories of Individualism". Thesis. University of South Florida Scholar Common (2007) : 1075 .

Botas, Paulo Charles Pimental. 'Sudents' Perception of Teachers'Pedagogical Styles in Higher Education”, Research Paper (2006) : 21.

Brennen, Anick. Essay on Education and Educational Pshycology. Booklet (Jamaica : Northern Caribean University : August, 2009). 
Carmelo "Paulo Freire Social Change and Teaching of Gothic Literature," College Quarterly 11,2 (Spring, 2008): 1- 10.

Chua, Amy. Battle Hymn of The Tiger Mother (New York : Penguin Group, 2011).

Dodge, Arnold. "Heuristic and NCLB Standardize Test' : A Convenience Lie", International Journal of Progressive Education 5,2, (2009) : 13, Retviered From Erick.

Ellias, John L. Paulo Freire, Pedagogue of Liberation (Florida : Kriegar Publishing Company, 1994).

Firdaus, Rau冈atul Binti Fatah Yasin and Jani, Mohd.Shah."Islamic Education: The Phylosophy, Aim, and Main Feature." International Journal of Education and Research 1,10 (Oktober, 2010):1-16.

Freire, Paulo. Pedagogy of the Oppressed Translated by Myra Bergman Ramos (New York: The Continuum International Publishing Group Inc, 2005 ).

Hamm, Ibrahim Mohammad. "Islamic Perspective of Education and Teachers", European Journal of Social Science 30,2 (2012): 220-228.

Hassad, Rossi A. Constructivist and Behaviorist Approaches: Development and Initial Evaluation of a Teaching Practice Scale for Introductory Statistics at the College Level," Advancing Education in Quantitative Literacy 4,2 (2011) :115.

Hruby, M "Freedom in Adult Education". Journal on Efficiency and Responsibility in Education and Science 1,2 (2008): 14,

Huitt, William G. dan lain-lain. “ Improving Student Achievement 1: A Systems-based Synthesis of Research Related to Improving Students' Academic Performance.". Paper presented at the 3rd International City Break Conference sponsored by the Athens Institute for Education and Research (ATINER), (October 16-19, 2009): 1-10. 
Imarah, Muhammad 'Imarah. al-Islām wa Huqūqu al-Insān (Beirut: 'Alim al- Ma'rifah, 1990).

Jābir, Muhammad Bn Sālam Bn 'Ali. "Ahdāf al-Tarbīyah al-Islamīyah wa Maqāsidihā." Maqālāt Muta'alliqah 355117 (12 Juli 2006) www.alukah.net (diakses pada tanggal 13 Juni 2014).

Kadenyi, Misia and Kariuki, Michael.” Rethinking Education for Liberation and Self-Reliance : An Examination of Nyere's and Plato's Paradigm", International Journal of Curriculum and Instruction 1,1 (April, 2011): 17

Madani, Abdul Hai. "Freedom and Its Concept in Islam." International Conference on Humanities, Historical and Social Sciences 17,2 (Singapore, 2011): 102-118.

Miller, William M. Reynolds Gloria E. Educational Psychology. Handbook of Psychology, Vol. 7 ( New Jersey : John Wiley \& Sons, Inc., 2003).

Muțțah>rī, Murțādā Insān-e Kāmil. Isfāhān : Markaze Tahqiqāt 'Abd Al-Latif, Mahmūd '. Al - Fikr al - Tarbawī 'Inda Ibn Sīnā. Abhāth Wa Naẓriyāt Tarbawiyah 50 ( 21/05/2014). Rayāne-i. www.Ghaemiyeh.com, tt : 12 (diakses pada tanggal 3 mei 2014).

-----. Yād-e Dāshtāhāee Ustād Muțțāhārī, Jild Aval, Harf Alef. Tehrān va Qum : Sadrā, 1978, 282 - 307.

-----. al-Tarbiyah wa al-Ta'lìm fi al-Islām. Beirut:Dār al- Hadi,tt.www. alameen-iq.com/book/akhlaq/29/f.htm(diakses pada tanggal 5 Mei 2014).

Naisaban, Ladislaus. Para Psikolog Terkemuka di Dunia (Jakarta :PT. Gramedia Widiasarana Indonesia, 2004).

Nelson, Jack L. "Academic Freedom, Institutional Integrity, and Teacher Education." Teacher Education Quarterly (Winter, 2003): 63.

Notoatmodjo, Soejidjo. Ilmu Perilaku Kesehatan (Jakarta : Rineka Cipta, 2010). 
Ohan, Christopher Ohan, "An Incompatible Method: The Western Liberal Arts Educational Model In Kuwait and The Arab Gulf Region". Journal of Educational and Social Research 2,3 (September, 2012): 43.

Ormond, JE. "Beyond Pavlop, Thorndike and Skinner': Other Early Behaviorist Theories," Pearson Education (2008).

Osman, Ahmad A. "Freedom in Teaching and Learning". International Journal of Humanities and Social Science 3,2 (Spesial Issue, January 2013): 147.

Pickard, Mary J. “The New Bloom's Taxonomy : An Overview for Family and Consumer Sciences." Journal of Family and Consumer Sciences Education. 25,1,(Spring/Summer 2007) : 1-49.

Pierce, W. David and Cheney, Carl D. Behavior Analysis and Learning. Third Edition (New Jersey : Lawrence Erlbaum Associates Publisher, 2004), 1-16.

Pring, Richard. Philosophy of Education (New York : Bookends, Ltd, Royston, 2005), 49-51.

Raygor, Robin. The Science of Psychology (New York : Mc-Graw hill University, 2005).

Şālih, Ali Abd al-Rahīm \}. "Al-'Iqāb al-Madrasī Al-Țarīqi Li al- Harb min Al-Madrasah." Hamalāt Al-Tamaddun, al-Tarbìyah wa al-Ta'lìm wa al-Bahthu al-'Amalī (02/1/20080).

Seifert, Kelvin Seifert and Sutton, Rosemary. Educational Psychology. Second Edition (Zurich, Switzerland : the Jacobs Foundation, 2009).

Shariati, Ali, Marxism and other Western Fallacies. Translated by R. Campbell. (Berkeley, Calif.: Mizan Press, 1980).

Stern, Sol "Paedagogy of the oppressor. Another Reason Why The US end Schools are so awful': the ongoing of Brazilian Maxist Paulo Freire", City Journal 19,2 (2009) : 1-8. 
Straus, Murray A. "Corporal Punishment and Primary Presentation of Physical Abuse," Child Abuse \& Neglect 24,9 (2000):10.

Storss, Debbie A. and Inderbitzin, Michelle "Imagining a Liberal Education: Criticcally the Learning Process Through Simulation", Journal of Transformative Eduation 4 (2006): 186.

Suseno, Franz Magniz. Etika Dasar, Masalah-masalah pokok Filsafat Moral (Jakarta : Kanisius, 1989).

Tropiano,Carmelo. "Paulo Freire, Social Change, and The Teaching of Gothic”. College Quarterly 11,2 (2009) : 3 